\title{
Metabolic syndrome and inflammation in adipose tissue occur at different times in animals submitted to a high-sugar/fat diet
}

\author{
Fabiane Valentini Francisqueti ${ }^{1}$, André Ferreira Nascimento ${ }^{2}$, Igor Otávio Minatel ${ }^{3}$, Marcos Correa Dias $^{2}$, \\ Renata de Azevedo Melo Luvizotto ${ }^{2}$, Carolina Berchieri-Ronchi ${ }^{1}$, Ana Lúcia A. Ferreira ${ }^{1}$ and \\ Camila Renata Corrêa ${ }^{1}$ \\ ${ }^{1}$ São Paulo State University (UNESP), Botucatu Medical School, Botucatu, São Paulo, Brazil \\ ${ }^{2}$ Institute of Health Sciences, Federal University of Mato Grosso (UFMT), Sinop, Mato Grosso, Brazil \\ ${ }^{3}$ São Paulo State University, Institute of Bioscience, Botucatu, São Paulo, Brazil
}

(Received 22 September 2016 - Final revision received 23 May 2017 - Accepted 29 June 2017)

Journal of Nutritional Science (2017), vol. 6, e41, page 1 of 8

doi:10.1017/jns.2017.42

Abstract

Obesity is associated with low-grade inflammation, triggered in adipose tissue, which may occur due to an excess of SFA from the diet that can be recognised by Toll-like receptor-4. This condition is involved in the development of components of the metabolic syndrome associated with obesity, especially insulin resistance. The aim of the study was to evaluate the manifestation of the metabolic syndrome and adipose tissue inflammation as a function of the period of time in which rats were submitted to a high-sugar/fat diet (HSF). Male Wistar rats were divided into six groups to receive the control diet (C) or the HSF for 6, 12 or 24 weeks. HSF increased the adiposity index in all HSF groups compared with the C group. HSF was associated with higher plasma TAG, glucose, insulin and leptin levels. Homeostasis model assessment increased in HSF compared with C rats at 24 weeks. Both TNF- $\alpha$ and IL- 6 were elevated in the epididymal adipose tissue of HSF rats at 24 weeks compared with HSF at 6 weeks and C at 24 weeks. Only the HSF group at 24 weeks showed increased expression of both Toll-like receptor-4 and NF- $\kappa$ B. More inflammatory cells were found in the HSF group at 24 weeks. We can conclude that the metabolic syndrome occurs independently of the inflammatory response in adipose tissue and that inflammation is associated with hypertrophy of adipocytes, which varies according to duration of exposure to the HSF.

Key words: Obesity: Adipocytes: Inflammation: Metabolic syndrome

The prevalence of obesity has increased strikingly during the past three decades, particularly among minorities and socioeconomically disadvantaged populations around the world ${ }^{(1-3)}$. The main factor that leads to this condition is overnutrition, especially when characterised by the excessive intake of carbohydrates and fat ${ }^{(4-9)}$, which can trigger the metabolic syndrome (MS) defined as a constellation of metabolic abnormalities for CVD and diabetes. A consensus agreement by the International Diabetes Federation and the American Heart Association/ National Heart, Lung and Blood Institute identifies the criteria of the MS as abdominal obesity, reduced HDL, elevated TAG, glucose intolerance and hypertension; a diagnosis requires any three of these five criteria ${ }^{(10)}$.

The primary cause of the MS appears to be increased adiposity associated with insulin resistance ${ }^{(11,12)}$. Furthermore, there is a strong relationship between obesity and inflammation ${ }^{(13)}$, since hyperadiposity produces adipokines, such as leptin, adiponectin and resistin, as well as proinflammatory cytokines such as IL-6, TNF- $\alpha$ and plasminogen activator inhibitor type 1 , which are all involved in proinflammatory and prothrombotic responses ${ }^{(14)}$.

Abbreviations: C, control diet; C24, control diet for 24 weeks; HOMA-IR, homeostasis model assessment; HSF, high-sugar/fat diet; HSF6, high-sugar/fat diet for 6 weeks; HSF12, high-sugar/fat diet for 12 weeks; HSF24, high-sugar/fat diet for 24 weeks; MS, metabolic syndrome; TLR-4, Toll-like receptor-4.

* Corresponding author: F. V. Francisqueti, fax +55 143881 6424, email fabiane_vf@yahoo.com.br 
In obesity, inflammation that is triggered in adipose tissue may occur due to the excess of SFA in the diet. These fatty acids can be recognised by Toll-like receptor-4 (TLR-4), which is expressed by adipocytes and macrophages, leading to activation of $\mathrm{NF}-\mathrm{KB}^{(15-18)}$, stimulating the production of chemokines and proinflammatory cytokines ${ }^{(19)}$, as well as attracting immune cells from the circulation into the adipose tissue $^{(16)}$. TLR-4 is a cell surface receptor that generates innate immune responses to pathogens by inducing signalling cascades of kinase and transcription factor activation, leading to the generation of proinflammatory cytokines, chemokines, eicosanoids and reactive oxygen species, all of which are effectors of innate immunity.

Thus, we can propose that excessive sugar and fat intake are factors that lead to inflammation in adipose tissue. Several studies have shown that inflammation is involved in the development of components of the MS associated with obesity, especially insulin resistance ${ }^{(20-22)}$. However, few experimental studies that have emphasised the role of diet, obesity and inflammation evaluated the participation of the TLR-4 pathway as a function of time ${ }^{(23-28)}$. Therefore, additional studies are needed to characterise the inflammatory response in adipose tissue and insulin resistance as a function of time. Thus, the aim of the present study was to evaluate the manifestation of the MS and inflammation adipose tissue as a function of time in rats submitted to a high-sugar/fat diet (HSF).

\section{Materials and methods}

\section{Animals and experimental protocol}

The experimental protocol was approved by the local Ethical Committee for Animal Research of the University of Sao Paulo State University (permit number PE-47/2011). Male Wistar rats (10 weeks old, $\pm 350 \mathrm{~g}$ ) from the Animal Center of Botucatu Medical School, Sao Paulo State University (UNESP, Botucatu, SP, Brazil), were assigned to either a commercial chow diet (control diet; C; $12 \%$ energy from fat) or an HSF (49.7\% energy from fat) with sucrose in the drinking water $(300 \mathrm{~g} / \mathrm{l})$ for a period of 6,12 or 24 weeks (C6, HSF6, C12, HSF12, C24, HSF24). The diet-induced obesity model was adapted from our previous study ${ }^{(29)}$ and it has been published previously ${ }^{(30)}$, which was used to mimic obesity from Western occidental dietary habits.

Rats were housed in individual cages in the animal facility at the Internal Medicine Experimental Laboratory, Botucatu Medical School, UNESP, under controlled ambient temperature $\left(22-26^{\circ} \mathrm{C}\right)$ and lighting $(12 \mathrm{~h}$ light $-12 \mathrm{~h}$ dark) conditions. Dietary and water consumption was measured daily, and body weight was assessed weekly. Energy intake was calculated according to the formula: energy intake $(\mathrm{kJ} / \mathrm{d})=$ food consumption $(\mathrm{g}) \times$ dietary energy $(\mathrm{kJ} / \mathrm{g})$. For the animals that received sucrose in drinking water (30\%), the energy intake was calculated according to the formula: volume consumed $(\mathrm{ml}) \times 0.3$ (equivalent to $30 \%$ sucrose) $\times 16.7(\mathrm{~kJ}$ per $\mathrm{g}$ of carbohydrate) + energy values offered by feeding (food consumption $(\mathrm{g}) \times$ dietary energy $(\mathrm{kJ} / \mathrm{g}))$.
The animals were killed by decapitation after anaesthesia with sodium pentobarbital Q4 (50 mg/kg, intraperitoneal injection) and all efforts were made to minimise suffering. Blood from fasted animals was collected in tubes containing EDTA and centrifuged at $3500 \mathrm{rpm}$ and the plasma was collected for analysis. Epididymal adipose tissue was selected for analysis because of its similar inflammatory patterns to visceral fat ${ }^{(31)}$.

\section{Adiposity index}

The adiposity index was used as an indicator of obesity because it enables the precise evaluation of body fat percentage. Epididymal, retroperitoneal and visceral fat deposits were dissected from the rats. The sum of the fat deposits, normalised by body weight, was calculated to obtain the adiposity index: ((epididymal + retroperitoneal + visceral $) /$ body weight $) \times 100^{(5,32)}$.

\section{Plasma analysis}

Biochemical. After $12 \mathrm{~h}$ of overnight fasting, plasma analysis were carried out. An enzymic colorimetric kit was used to measure glucose (Bioclin ${ }^{\circledR}$; Belo Horizonte), TAG (Bioclin ${ }^{\circledR}$; Belo Horizonte) and NEFA (WAKO ${ }^{\circledR}$; HR Series NEFA$\mathrm{HR}^{(2)}$. Spectrophotometry was performed with the Chemistry Analyser BS 200 automatic spectrophotometer (Mindray Medical International Ltd).

Insulin resistance. Insulin resistance was determined using the index of homeostasis model assessment (HOMA-IR) using the following formula ${ }^{(33)}$ : HOMA-IR = fasting insulin $(\mu \mathrm{U} / \mathrm{ml}) \times$ fasting glucose $(\mathrm{mmol} / \mathrm{l}) / 22 \cdot 5$.

Hormones and inflammatory cytokines. Plasma levels of insulin, leptin, adiponectin, TNF- $\alpha$ and IL-6 were measured by ELISA. Insulin, leptin and adiponectin ELISA kits were purchased from Millipore Corporation and TNF- $\alpha$ and IL-6 ELISA kits were purchased from R\&D Systems. A microplate spectrophotometer reader (SpectraMax 190; Molecular Devices) was used according to the manufacturer's instructions.

\section{Analysis of epididymal adipose tissue}

Adipokine levels. Epididymal adipose tissue (400 mg) was triturated with $2 \mathrm{ml}$ of PBS ( $\mathrm{pH} \mathrm{7.4)}$ and then centrifuged at $3000 \mathrm{rpm}$ and $4^{\circ} \mathrm{C}$ for $10 \mathrm{~min}$. Using the supernatants, TNF- $\alpha$ and IL- 6 were measured using commercial ELISA kits (R\&D Systems) according to the manufacturer's instructions. The results were normalised to protein amounts of each sample, quantified by the Bradford method ${ }^{(34)}$.

Western blotting. The protein concentration of the whole epididymal adipose tissue extract (including the cell membrane, cytoplasm and nucleus) was determined by the Bradford method ${ }^{(34)}$. Samples $(25 \mu \mathrm{g}$ of protein) were heated 
in Laemmli buffer at $100^{\circ} \mathrm{C}$ for $5 \mathrm{~min}$, then loaded onto a 10 $\%$ SDS-polyacrylamide gel. Transfer to a nitrocellulose membrane was carried out at $4^{\circ} \mathrm{C}$ in the presence of methanol. Incubation with the primary antibodies (purchased from Santa Cruz Biotechnology) was performed overnight at $4^{\circ} \mathrm{C}$ in Tris-buffered saline solution containing Tween 20 (TBS-T) and 3\% non-fat dried milk. Antibody dilutions were: 1:200 for mouse anti-TLR-4 sc293072, 1:200 for mouse anti- $\beta$-actin sc47778, $1: 100$ for rabbit antiphosphorylated NF- $\mathrm{B}$ (ser536) sc33020, and 1:200 for mouse anti-total NF- $\mathrm{B}$ sc8008. After incubation overnight at $4{ }^{\circ} \mathrm{C}$ in TBS-T containing $1 \%$ non-fat dried milk with the Abcam secondary antibodies (dilution 1:10000) anti-rabbit ab97069 and anti-mouse ab98808, protein was revealed using the chemiluminescence method according to the manufacturer's instructions (ECL SuperSignal ${ }^{\circledR}$ West Pico Chemiluminescent Substrate; Thermo Scientific). Band intensities were evaluated using Scion Image Software (Scion Corporation).

\section{Histological analysis}

Adipose tissue was fixed in $4 \%$ formaldehyde and embedded in paraffin. Two consecutive sections from each sample were cut $(4 \mu \mathrm{m})$ and stained with haematoxylin/eosin. The entire slide was scanned using a 3DHISTECH Panoramic MIDI System attached to a Hitachi HV-F22 colour camera and ten fields/slide were analysed under $40 \times$ magnification in a blinded manner. The inflammatory reactions are reported as the number of inflammatory cells per high-power field. Using the same slides, the mean area of adipocytes was calculated using a method previously described by Osman et al. in $2013^{(35)}$.

\section{Statistical analysis}

Results are expressed as means and standard deviations. Comparisons among groups were performed using two-way ANOVA for independent groups and were completed using Tukey's post hoc test. SigmaPlot 11.0 software (Systat Software Inc.) was used for statistical analyses. Differences were considered significant at $P<0 \cdot 05$. The statistical power for the main outcome variables was above $80 \%$.

\section{Results}

\section{Body weight and body fat}

There was no difference in energy intake between the $\mathrm{C}$ and HSF groups at any time (Table 1). The HSF caused changes in the body composition of the animals. At the end of 24 weeks, the HSF group had a greater average weight than the rats in the C24, HSF6 and HSF12 groups. The adiposity index was higher in all HSF groups compared with their respective controls, and in HSF12 and HSF24 compared with HSF6 (Table 1).

\section{Plasma biochemical and hormonal measurements}

An increase in TAG, glucose, insulin and leptin levels and a decreased level of adiponectin was detected in all animals in the HSF group compared with the $\mathrm{C}$ rats. However, when comparing animals subjected to the same diet for different periods of time, only leptin was increased in HSF12 and HSF24 rats compared with the HSF6 group. Animals that received HSF showed insulin resistance only at 24 weeks compared with control animals characterised by increased HOMA-IR (Table 2). There was no difference in NEFA levels among the groups.

Table 1. Nutritional profile of the control diet (C) group and high-sugar/fat diet (HSF) groupt (Mean values and standard deviations, $n 8$ )

\begin{tabular}{|c|c|c|c|c|c|c|c|c|c|c|c|c|c|c|c|}
\hline \multirow[b]{3}{*}{ Variables } & \multicolumn{12}{|c|}{ Group } & \multirow[b]{3}{*}{$P$ diet } & \multirow[b]{3}{*}{$P$ time } & \multirow[b]{3}{*}{$P$ interaction } \\
\hline & \multicolumn{2}{|c|}{ C6 } & \multicolumn{2}{|c|}{ HSF6 } & \multicolumn{2}{|c|}{$\mathrm{C} 12$} & \multicolumn{2}{|c|}{ HSF12 } & \multicolumn{2}{|c|}{$\mathrm{C} 24$} & \multicolumn{2}{|c|}{ HSF24 } & & & \\
\hline & Mean & SD & Mean & $\mathrm{SD}$ & Mean & SD & Mean & SD & Mean & SD & Mean & SD & & & \\
\hline IBW (g) & $348 \cdot 8$ & 40.5 & $350 \cdot 4$ & 33.0 & 349.5 & $28 \cdot 8$ & $344 \cdot 2$ & $23 \cdot 1$ & $352 \cdot 8$ & 33.3 & $350 \cdot 0$ & 22.5 & 0.81 & 0.91 & 0.25 \\
\hline FBW $(g)$ & $456 \cdot 0^{A}$ & 38.0 & $469 \cdot 0^{\mathrm{a}}$ & $40 \cdot 3$ & $499 \cdot 3^{A}$ & $42 \cdot 3$ & $562 \cdot 7^{b}$ & 54.0 & $568 \cdot 4^{\mathrm{B}}$ & $66 \cdot 7$ & $708 \cdot 0^{\star c}$ & $69 \cdot 1$ & $<0.001$ & $<0.001$ & 0.006 \\
\hline Weight gain $(\mathrm{g})$ & $107 \cdot 2^{\mathrm{A}}$ & 19.7 & $118 \cdot 6^{\mathrm{a}}$ & 32.0 & $149.9^{A}$ & 29.7 & $218 \cdot 5^{\star b}$ & 57.7 & $215 \cdot 6^{\mathrm{B}}$ & $58 \cdot 7$ & $358 \cdot 0^{\star c}$ & $72 \cdot 1$ & $<0.001$ & $<0.001$ & 0.002 \\
\hline Epididymal (g) & $7 \cdot 0^{\mathrm{A}}$ & 1.8 & $10 \cdot 8^{\star a}$ & 3.2 & $8.9^{A}$ & $2 \cdot 2$ & $18 \cdot 4^{\star \mathrm{b}}$ & $5 \cdot 3$ & $11 \cdot 7^{\mathrm{B}}$ & 4.4 & $26 \cdot 7^{\star \mathrm{c}}$ & 7.4 & $<0.001$ & $<0.001$ & 0.7983 \\
\hline Retroperitoneal (g) & $8.0^{\mathrm{A}}$ & $2 \cdot 6$ & $15 \cdot 6^{\star a}$ & 5.3 & $10 \cdot 7^{\mathrm{B}}$ & 4.6 & $24 \cdot 7^{\star b}$ & $7 \cdot 3$ & $12 \cdot 2^{\mathrm{B}}$ & 4.7 & $26 \cdot 7^{\star \mathrm{C}}$ & 7.4 & $<0.001$ & 0.0010 & 0.6688 \\
\hline Visceral $(\mathrm{g})$ & $5.8^{\mathrm{A}}$ & 1.8 & $9.9^{\star a}$ & 3.4 & $8 \cdot 1^{B}$ & 2.5 & $16 \cdot 8^{* b}$ & 6.4 & $9 \cdot 8^{\mathrm{B}}$ & 3.7 & $24 \cdot 0^{* \mathrm{C}}$ & 5.7 & $<0.001$ & $<0.001$ & 0.9074 \\
\hline Total body fat (g) & $20 \cdot 9^{A}$ & 5.9 & $36 \cdot 4^{\star a}$ & 11.6 & $27 \cdot 7^{A}$ & 8.5 & $59 \cdot 9^{* b}$ & 17.4 & $36 \cdot 6^{A}$ & $12 \cdot 7$ & $94 \cdot 8^{\star \mathrm{C}}$ & 25.6 & $<0.001$ & $<0.001$ & 0.001 \\
\hline Adiposity index (\%) & $4.5^{\mathrm{A}}$ & 1.0 & $7 \cdot 6^{\star a}$ & 1.8 & $5 \cdot 5^{\mathrm{A}}$ & 1.5 & $10 \cdot 5^{\star b}$ & 2.3 & $5 \cdot 8^{\mathrm{B}}$ & 1.7 & $10 \cdot 9^{* c}$ & 2.3 & $<0.001$ & 0.0029 & 0.9288 \\
\hline Food intake $(\mathrm{g} / \mathrm{d})$ & $28 \cdot 3$ & 2.9 & $12 \cdot 3^{*}$ & 2.0 & $27 \cdot 7$ & $2 \cdot 2$ & $12 \cdot 7^{\star}$ & $2 \cdot 1$ & 29.9 & 4.1 & $15 \cdot 7^{\star}$ & 1.4 & $<0.001$ & 0.0060 & 0.6283 \\
\hline Water intake $(\mathrm{ml} / \mathrm{d})$ & $35 \cdot 8$ & $5 \cdot 0$ & $27.9^{\mathrm{A}}$ & 7.5 & $36 \cdot 6$ & 4.6 & $29 \cdot 4^{\mathrm{A}}$ & $8 \cdot 8$ & $45 \cdot 3$ & $5 \cdot 3$ & $43 \cdot 2^{B}$ & $8 \cdot 8$ & 0.0064 & $<0.001$ & 0.3913 \\
\hline \multicolumn{16}{|l|}{ Energy intake } \\
\hline $\mathrm{kcal} / \mathrm{d}$ & 106.6 & $10 \cdot 8$ & 94.6 & 11.4 & 104.3 & 8.2 & 99.9 & $10 \cdot 6$ & $107 \cdot 2$ & $12 \cdot 4$ & 102.5 & 9.5 & 0.2032 & 0.4762 & 0.5623 \\
\hline $\mathrm{kJ} / \mathrm{d}$ & 446.0 & 45.2 & 395.8 & 47.7 & 436.4 & 34.3 & 418.0 & 44.4 & 448.5 & 51.9 & 428.9 & 39.7 & 0.2032 & 0.4762 & 0.5623 \\
\hline
\end{tabular}

C6, control diet for 6 weeks; HSF6, high-sugar/fat diet for 6 weeks; C12, control diet for 12 weeks; HSF12, high-sugar/fat diet for 12 weeks; C24, control diet for 24 weeks; HSF24, high-sugar/fat diet for 24 weeks; IBW, initial body weight; FBW, final body weight.

$\mathrm{A}, \mathrm{B}$ Mean values within a row with unlike uppercase letters were significantly different among the $\mathrm{C}$ groups $(6 \mathrm{v} .12 \mathrm{v} .24 \mathrm{weeks})(P<0.05)$.

a,b,c Mean values within a row with unlike lowercase letters were significantly different among the HSF groups $(6 \mathrm{v} .12 \mathrm{v} .24$ weeks $)(P<0.05)$.

* Mean value was significantly different from that for the $C$ group at the same time point $(P<0.05)$.

† Comparisons among groups were performed using two-way ANOVA for independent groups and were completed using Tukey's post hoc test. 
Table 2. Plasma biochemical and hormonal measurements $\dagger$ (Mean values and standard deviations, $n 8$ )

\begin{tabular}{|c|c|c|c|c|c|c|c|c|c|c|c|c|c|c|c|}
\hline \multirow[b]{3}{*}{ Variables } & \multicolumn{12}{|c|}{ Groups } & \multirow[b]{3}{*}{$P$ diet } & \multirow[b]{3}{*}{$P$ time } & \multirow[b]{3}{*}{$P$ interaction } \\
\hline & \multicolumn{2}{|c|}{$\mathrm{C} 6$} & \multicolumn{2}{|c|}{ HSF6 } & \multicolumn{2}{|c|}{$\mathrm{C} 12$} & \multicolumn{2}{|c|}{ HSF12 } & \multicolumn{2}{|c|}{$\mathrm{C} 24$} & \multicolumn{2}{|c|}{ HSF24 } & & & \\
\hline & Mean & SD & Mean & SD & Mean & SD & Mean & SD & Mean & SD & Mean & SD & & & \\
\hline TAG (mmol/l) & $0.47^{A, B}$ & 0.13 & $1.03^{* a, b}$ & 0.32 & $0.43^{\mathrm{A}}$ & 0.04 & $0.93^{\star a}$ & 0.25 & $0.58^{\mathrm{B}}$ & 0.17 & $1 \cdot 14^{\star b}$ & 0.25 & $<0.001$ & 0.0150 & 0.2970 \\
\hline $\mathrm{NEFA}(\mathrm{mmol} / \mathrm{l})$ & 0.3 & 0.1 & 0.3 & 0.1 & 0.4 & 0.1 & 0.4 & 0.1 & 0.3 & 0.1 & 0.4 & 0.1 & 0.0192 & 0.0515 & 0.4190 \\
\hline Glucose $(\mathrm{mmol} / \mathrm{l})$ & 4.77 & 0.58 & $5 \cdot 68^{*}$ & 0.40 & 6.53 & $1 \cdot 17$ & $7 \cdot 77^{\star}$ & 1.39 & $5 \cdot 38$ & 0.04 & $6 \cdot 51^{*}$ & 0.71 & $<0.001$ & 0.0069 & 0.7055 \\
\hline Insulin (ng/ml) & 1.9 & 0.8 & $3.9^{\star}$ & 1.6 & $2 \cdot 7$ & $2 \cdot 1$ & $4 \cdot 2^{*}$ & $1 \cdot 3$ & 2.4 & 0.8 & $5.4^{*}$ & $1 \cdot 6$ & $<0.001$ & 0.1487 & 0.3074 \\
\hline HOMA-IR & 0.9 & 0.5 & 3.8 & $2 \cdot 5$ & 2.5 & 4.4 & 4.2 & $2 \cdot 4$ & 1.4 & $1 \cdot 1$ & $7 \cdot 0^{*}$ & 4.8 & $<0.001$ & 0.232 & 0.194 \\
\hline Leptin (ng/ml) & $2 \cdot 5^{\mathrm{A}}$ & 0.8 & $6 \cdot 2^{* a}$ & 0.8 & $2 \cdot 8^{\mathrm{A}, \mathrm{B}}$ & 0.7 & $11 \cdot 4^{\star \mathrm{b}}$ & $5 \cdot 8$ & $3 \cdot 7^{\mathrm{B}}$ & 2.4 & $13 \cdot 9^{* b}$ & $3 \cdot 2$ & $<0.001$ & 0.0053 & 0.5502 \\
\hline Adiponectin (ng/ml) & $19 \cdot 4$ & $7 \cdot 2$ & $11.4^{*}$ & 1.6 & $20 \cdot 1$ & 4.4 & $11 \cdot 7^{*}$ & $2 \cdot 6$ & $19 \cdot 0$ & 4.0 & $13 \cdot 1^{*}$ & $1 \cdot 6$ & $<0.001$ & 0.724 & 0.370 \\
\hline
\end{tabular}

C6, control diet for 6 weeks; HSF6, high-sugar/fat diet for 6 weeks; C12, control diet for 12 weeks; HSF12, high-sugar/fat diet for 12 weeks; C24, control diet for 24 weeks; HSF24, high-sugar/fat diet for 24 weeks; HOMA-IR, homeostasis model assessment.

$\mathrm{A}, \mathrm{B}$ Mean values within a row with unlike uppercase letters were significantly different among the $\mathrm{C}$ groups $(6 \mathrm{v} .12 \mathrm{v} .24$ weeks $)(P<0.05)$

${ }^{a, b}$ Mean values within a row with unlike lowercase letters were significantly different among the HSF groups $(6 \mathrm{v} .12 \mathrm{v} .24$ weeks $)(P<0.05)$

* Mean value was significantly different from that for the $\mathrm{C}$ group at the same time point $(P<0.05)$.

† Comparisons among groups were performed using two-way ANOVA for independent groups and were completed using Tukey's post hoc test.

\section{Adipose tissue and serum adipokine measurements}

No differences were found in the plasma levels of TNF- $\alpha$ and IL-6 when comparing different diets or different durations (data not shown). In adipose tissue, animals in the HSF24 group exhibited elevated levels of these cytokines compared with the C24 group, as well as the HSF6 and HSF12 groups (Fig. 1). However, HSF12 had lower levels of TNF- $\alpha$ and IL-6 compared with C12.

\section{Adipose tissue area}

Table 3 shows the mean area of adipocytes in control animals and those fed the HSF in the three periods of the experiment. Note that there was an increase in the area of the adipocytes in animals fed the HSF only at 24 weeks compared with the C24, HSF6 and HSF12 groups. Fig. 2 shows images taken for the assessment of inflammatory cell infiltration. A greater number of cells was observed in the HSF24 group.

\section{Western blotting}

Fig. 3 shows the protein expression of TLR- 4 and NF- $\kappa B$ in epididymal adipose tissue. At the end of 24 weeks, the animals in the HSF24 group showed higher TLR-4 expression than those in the C24 and HSF6 groups. Similar to TLR-4, the expression of NF- $\mathrm{\kappa B}$ increased in epididymal adipose tissue after 24 weeks in the HSF group when compared with animals in the $\mathrm{C} 24$ group.

\section{Discussion}

In the present study using Wistar male rats fed an HSF, we evaluated the temporal relationship between the manifestation of metabolic parameters and the effects of inflammation in adipose tissue via TLR-4. According to the WHO, obesity is defined as an excessive accumulation of body fat ${ }^{(36)}$. In 2014, Strissel et al. ${ }^{(37)}$ associated obesity with chronic lowgrade inflammation, called metainflammation ${ }^{(38)}$, which differs from the classic inflammatory response against injury or pathogens ${ }^{(39)}$. Chronic consumption of an HSF is associated with metabolic changes, since it triggers an increase in body weight and obesity ${ }^{(9)}$. These factors are associated with high blood pressure, as well as biochemical and hormonal changes, such as increased blood glucose, TAG, NEFA, leptin and insulin, as well as reduced adiponectin ${ }^{(40,41)}$. However, it is still unclear how the duration of this diet is related to metabolic
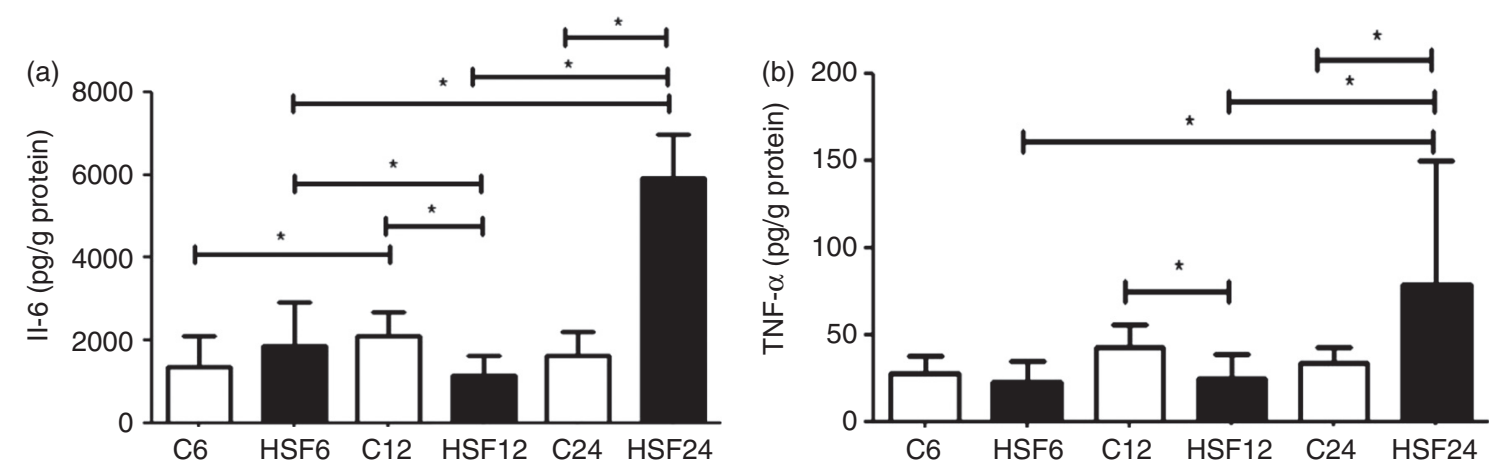

Fig. 1. Cytokine levels (pg/g protein) in epididymal adipose tissue in control diet (C) and high-sugar/fat diet (HSF) groups over 6 , 12 and 24 weeks ( $n 8$ animals/ group). (a) IL-6 level; (b) TNF- $\alpha$ level. Values are means, with standard deviations represented by vertical bars. ${ }^{*}$ Mean values were significantly different $(P<0.05)$. 
Table 3. Mean area of adipocytes in epididymal adipose tissue of control diet (C) and high-sugar/fat diet (HSF) groups $\dagger$ (Mean values and standard deviations, $n 8$ )

\begin{tabular}{|c|c|c|c|c|c|c|}
\hline \multirow[b]{2}{*}{ Group } & \multicolumn{2}{|c|}{$\begin{array}{c}\text { Area of } \\
\text { adipocytes }\left(\mathrm{mm}^{2}\right)\end{array}$} & \multirow[b]{2}{*}{ Number of inflammatory cells/field } & \multirow[b]{2}{*}{$P$ diet $<0.001$} & \multirow[b]{2}{*}{$P$ time $<0.001$} & \multirow[b]{2}{*}{$P$ interaction 0.004} \\
\hline & Mean & SD & & & & \\
\hline C6 & $1.0^{\mathrm{A}}$ & 0.2 & $1-5$ & & & \\
\hline HSF6 & $1.4^{\mathrm{a}}$ & 0.2 & $1-5$ & & & \\
\hline C12 & $1 \cdot 1^{\mathrm{A}}$ & 0.4 & $1-5$ & & & \\
\hline HSF12 & $1 \cdot 4^{\mathrm{a}}$ & 0.1 & $20-40$ & & & \\
\hline $\mathrm{C} 24$ & $2 \cdot 8^{\mathrm{B}}$ & 1.2 & $5-20$ & & & \\
\hline HSF24 & $5 \cdot 0^{* \mathrm{~b}}$ & 0.9 & $>40$ & & & \\
\hline
\end{tabular}

C6, control diet for 6 weeks; HSF6, high-sugar/fat diet for 6 weeks; C12, control diet for 12 weeks; HSF12, high-sugar/fat diet for 12 weeks; C24, control diet for 24 weeks; HSF24, high-sugar/fat diet for 24 weeks.

A,B Mean values within a column with unlike uppercase letters were significantly different among the $C$ groups $(6 \mathrm{v} .12 \mathrm{v} .24$ weeks) $(P<0<05)$.

a,b Mean values within a column with unlike lowercase letters were significantly different among the HSF groups $(6 \mathrm{v} .12 \mathrm{v}$. 24 weeks $)(P<0.05)$.

* Mean value was significantly different from that for the $\mathrm{C}$ group at the same time point $(P<0.05)$.

† Comparisons among groups were performed using two-way ANOVA for independent groups and were completed using Tukey's post hoc test.

changes and whether these changes occur before or after inflammation.

HOMA-IR has been used to assess overall insulin sensitivity in human subjects and rats with different degrees of insulin sensitivity $^{(42)}$. Therefore, HOMA-IR is a good predictor of whole-body insulin sensitivity. In our study, the modification of parameters including glucose, TAG, leptin and insulin, as well as low adiponectin, started as early as 6 weeks on the diet. There was also a greater adiposity index observed in these animals. All these conditions persisted up to 24 weeks, even without higher energy intake. This underscores the notion that diet components are an important factor in the manifestation of the MS. The HSF is a combination of palatable foods with high energy density, reflecting the Western dietary pattern. These data corroborate the HSF as a trigger of metabolic and hormonal changes, abdominal circumference, and expansion of fat mass ${ }^{(43,44)}$. More specifically, a higher proportion of SFA (myristic (C14), palmitic (C16) and stearic (C18)) in relation to unsaturated fats (mono- and polyunsaturated) is associated with high adiposity and central fat deposit ${ }^{(45)}$. High levels of carbohydrates are also able to mobilise fat from the periphery to central deposits and reduce the activity of adiponectin in peripheral tissues ${ }^{(46)}$. When there is an expansion of fat mass, there is also adipocyte hypertrophy, which is responsible for the production of adipokines, including TNF- $\alpha$ and IL- $6^{(47)}$. In our work, at 6 and 12 weeks,

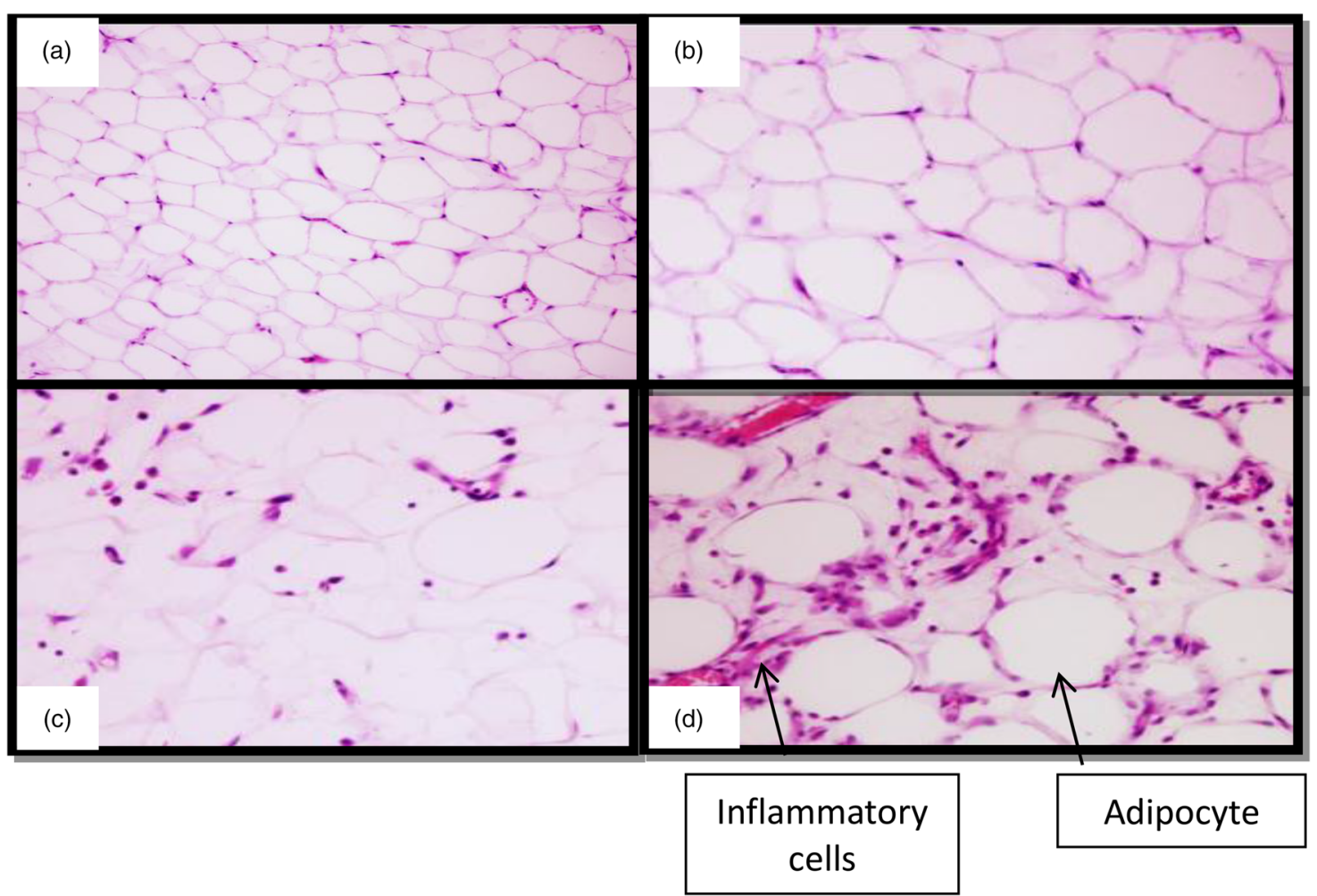

Fig. 2. Inflammatory cells in adipose tissue. (a) Control group; (b) group fed high-sugar/fat diet for 6 weeks (HSF6); (c) group fed high-sugar/fat diet for 12 weeks (HSF12); (d) group fed high-sugar/fat diet for 24 weeks (HSF24) ( $n 8$ animals/group). 40x Magnification. 

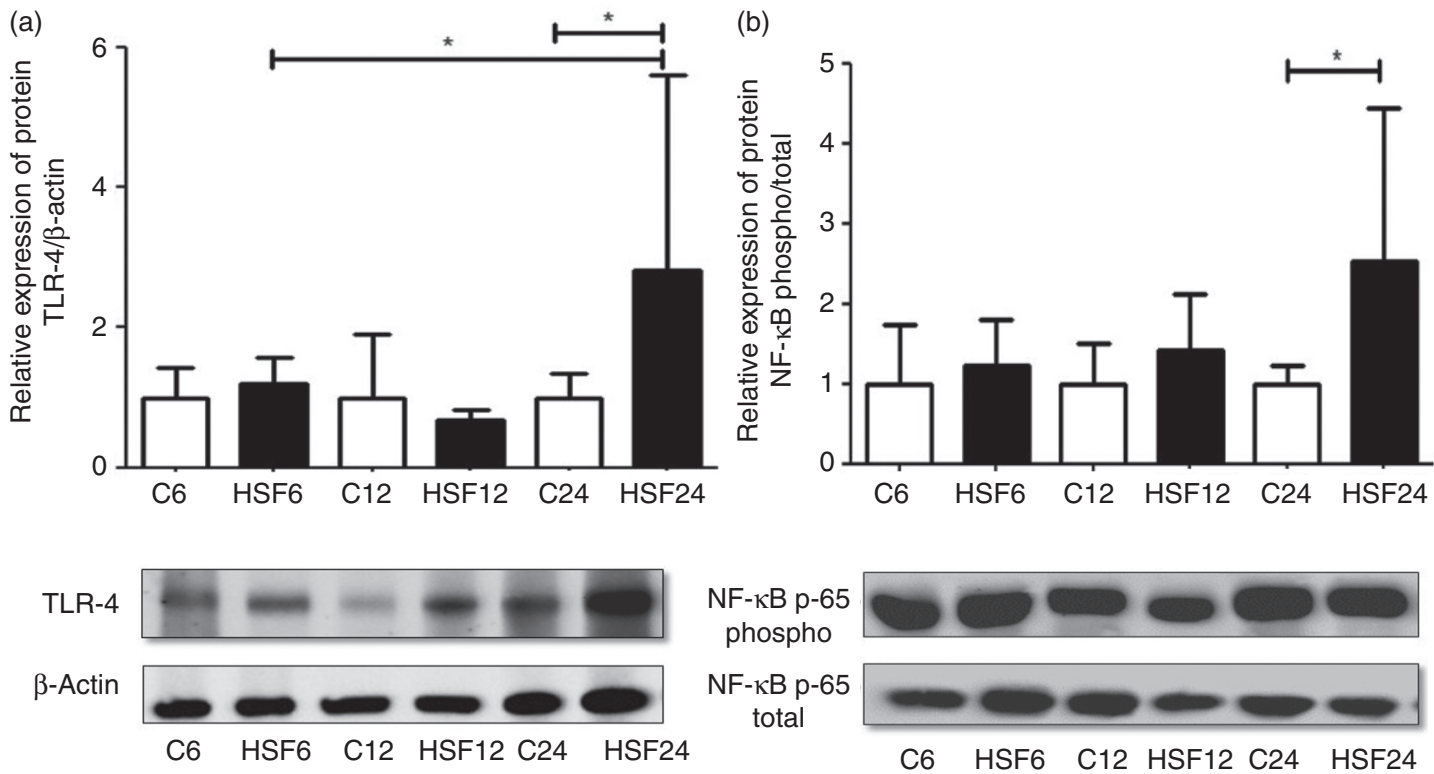

Fig. 3. Relative expression of protein in epididymal adipose tissue in control diet (C) and high-sugar/fat diet (HSF) groups over 6 , 12 and 24 weeks ( $n 8$ animals/ group). (a) Toll-like receptor-4 (TLR-4); (b) NF-кB. Values are means, with standard deviations represented by vertical bars. * Mean values were significantly different $(P<0.05)$.

although the animals presented an increase in the adiposity index, hypertrophy was not present and was only observed at 24 weeks, accompanied by inflammation and increased TNF- $\alpha$ and IL-6 levels. Therefore, the inflammatory state was observed only together with adipocyte hypertrophy, suggesting that adipose tissue is made up of mature and immature adipocytes (low fat content). Under excessive energy supply conditions, immature adipocytes would be responsible for the accumulation of fat, giving the adipose tissue a uniform appearance that still does not characterise hypertrophy.

Two distinct macrophage populations can be identified in adipose tissue: M1 and M2 ${ }^{(48)}$. The M1 profile produces proinflammatory cytokines that affect cell proliferation and promote insulin resistance, while the M2 population is associated with an anti-inflammatory phenotype that protects against metabolic disorders ${ }^{(49,50)}$. Lean individuals express a balance in the M1/M2 profile in adipose tissue, while obese individuals initially show an increase in the M2 profile, a defence mechanism to combat possible inflammation ${ }^{(50)}$. Our data show that, at 12 weeks, the animals showed a reduction in TNF- $\alpha$ and IL-6, providing evidence for this compensatory response in adipose tissue. This mechanism can occur to reduce inflammation and metabolic deterioration of the tissue. However, at 24 weeks, due to the hypertrophy of adipocytes and increased body fat, a shift may have occurred in the profile of these macrophages towards M1, causing an increase in proinflammatory cytokines. Corroborating this hypothesis, a murine study by Shaul et al. ${ }^{(51)}$ also showed an enhanced M2 phenotype in adipose tissue in obese mice after 12 weeks on a highfat diet compared with mice fed the same diet for 8 weeks.

Increased adiposity is associated with the activation and migration of inflammatory cells into the adipose tissue, as well as proinflammatory cytokine secretion and development of low-grade chronic inflammation ${ }^{(52)}$. Besides the hypertrophy of adipose tissue and macrophage profile in tissue, another factor that can enhance this inflammatory condition is the activation of TLR-4 receptors ${ }^{(19)}$. Our results show an increase in expression of adipocytes at 24 weeks. The literature shows that this activation can occur by an increased release of fatty acids by adipose tissue, by SFA intake ${ }^{(51)}$ or by the change in intestinal flora and lipopolysaccharide stimulus ${ }^{(53)}$. In the present study, we can attribute the increase in TLR-4 to the dietary fat stimulus, since elevated NEFA in circulation were not found. TLR-4 activates the transcription factor $N F-\kappa B$, leading to increased production of proinflammatory cytokines $^{(54)}$, reinforcing the importance of this pathway.

In obesity, the degree of inflammation correlates with the extent of insulin resistance, a mechanism involving TNF- $\alpha$, which interferes with the phosphorylation of the insulin receptor, impairing its glucose uptake function ${ }^{(55)}$. Our work shows that insulin resistance is present, together with the inflammatory response, in adipose tissue after 24 weeks, along with adipocyte hypertrophy. Thus, these data allow us to hypothesise that insulin resistance is influenced by inflammation of the adipose tissue, which in turn is associated with adipocyte hypertrophy and TLR-4 activation. We can conclude that the MS occurs independently of inflammation in adipose tissue and that inflammation is associated with adipocyte hypertrophy, which varies according to the duration of exposure to an HSF.

\section{Final considerations}

Although the present study was carried out in rats, the mechanisms related to the development of the MS and inflammation may be similar to those involved in clinical obesity, since after the onset of inflammation in adipose tissue, dependent on adipocyte hypertrophy, the organism may develop new co-morbidities over time, and potentiate the preexisting ones. The results of the present study are clinically important because they provide information that may promote 
interventions to prevent adipocyte hypertrophy and inflammation, being a preventive measure in the development of co-morbidities arising from this process.

\section{Acknowledgements}

We thank Mario B. Bruno, José Carlos Georgette and Renata Capela for their technical support.

We thank Fundação de Amparo a Pesquisa do Estado de São Paulo - FAPESP (2011/14132-0, 2011/14593-8, 2015/ 10626-0) for providing financial support.

The author contributions were as follows: A. F. N. and C. R. C. designed the research; F. V. F., C. B.-R., I. O. M., M. C. D., R. A. M. L. and A. L. A. F. conducted the research; A. F. N. and C. R. C. analysed the data; F. V. F., A. F. N. and C. R. C. wrote the paper.

The authors declare no conflicts of interest.

\section{References}

1. Flegal KM, Carroll MD, Ogden CL, et al. (2010) Prevalence and trends in obesity among us adults, 1999-2008. J Am Med Assoc 303, 235-241.

2. Sowers JR (2003) Obesity as a cardiovascular risk factor. Am J Med 115, Suppl. 8A, 37S-41S.

3. Whaley-Connell A, Pulakat L, Demarco VG, et al. (2011) Overnutrition and the cardiorenal syndrome: use of a rodent model to examine mechanisms. CardioRenal Med 1, 23-30.

4. Carvalheira JBC, Calegari VC, Zecchin HG, et al. (2003) The crosstalk between angiotensin and insulin differentially affects phosphatidylinositol 3-kinase- and mitogen-activated protein kinasemediated signaling in rat heart: implications for insulin resistance. Endocrinology 144, 5604-5614.

5. Boustany CM, Bharadwaj K, Daugherty A, et al. (2004) Activation of the systemic and adipose renin-angiotensin system in rats with diet-induced obesity and hypertension. Am J Physiol Regul Integr Comp Physiol 287, R943-R949.

6. Quatanani M \& Lazar MA (2016) Mechansims of obesity-associated insulin resistance: many choice on the menu. Genes Dev 215, 1443-1455.

7. Govindarajan G, Hayden MR, Cooper SA, et al. (2006) Metabolic derangements in the insulin-resistant heart. J Cardiometab Syndr 1, 102-106.

8. Ren J, Sowers JR, Walsh MF, et al. (2000) Reduced contractile response to insulin and IGF-I in ventricular myocytes from genetically obese Zucker rats. Am J Physiol Heart Circ Physiol 279, H1708H1714.

9. Hwi JK, Zhang Z, Dae YJ, et al. (2009) Nutrient stress activates inflammation and reduces glucose metabolism by suppressing AMP-activated protein kinase in the heart. Diabetes 58, 25362546.

10. Alberti KG, Eckel RH, Grundy SM, et al. (2009) Harmonizing the metabolic syndrome: a joint interim statement of the International Diabetes Federation Task Force on Epidemiology and Prevention; National Heart, Lung, and Blood Institute; American Heart Association; World Heart Federation; International Atherosclerosis Society; and International Association for the Study of Obesity. Circulation 120, 1640-1645.

11. Gonçalves CG, Glade MJ \& Meguid MM (2016) Metabolically healthy obese individuals: key protective factors. Nutrition 32, 14-20.

12. Mayans L (2015) Metabolic syndrome: insulin resistance and prediabetes. FP Essent 435, 11-16.

13. Dupuy AM, Jaussent I, Lacroux A, et al. (2007) Waist circumference adds to the variance in plasma C-reactive protein levels in elderly patients with metabolic syndrome. Gerontology 53, 329-339.
14. Yudkin JS (1999) Abnormalities of coagulation and fibrinolysis in insulin resistance. Evidence for a common antecedent? Diabetes Care 22, Suppl. 3, C25-C30.

15. Hwang D (2001) Modulation of the expression of cyclooxygenase-2 by fatty acids mediated through Toll-like receptor 4-derived signaling pathways. FASEB J 15, 2556-2564.

16. Kim JJ \& Sears DD (2010) TLR4 and insulin resistance. Gastroenterol Res Pract 2010, article ID 212563.

17. Silver AC, Kikuchi Y, Fadl AA, Sha J, et al. (2007) Interaction between innate immune cells and a bacterial type III secretion system in mutualistic and pathogenic associations. Proc Natl Acad Sci U $S$ A 104, 9481-9486.

18. Zeyda M \& Stulnig TM (2009) Obesity, inflammation, and insulin resistance - a mini-review. Gerontology 55, 379-386.

19. Cai D, Yuan M, Frantz DF, et al. (2005) Local and systemic insulin resistance resulting from hepatic activation of IKK- $\beta$ and NF-KB. Nat Med 11, 183-190.

20. Marette A (2002) Mediators of cytokine-induced insulin resistance in obesity and other inflammatory settings. Curr Opin Clin Nutr Metab Care 5, 377-383.

21. Dandona P \& Aljada A (2002) A rational approach to pathogenesis and treatment of type 2 diabetes mellitus, insulin resistance, inflammation, and atherosclerosis. Am J Cardiol 90, 27G-33G.

22. Festa A, D'Agostino R, Howard G, et al. (2000) Chronic subclinical inflammation as part of the insulin resistance syndrome: the Insulin Resistance Atherosclerosis Study (IRAS). Circulation 102, 42-47.

23. Maric T, Woodside B \& Luheshi GN (2014) The effects of dietary saturated fat on basal hypothalamic neuroinflammation in rats. Brain Behav Immun 36, 35-45.

24. Kim SJ, Choi Y, Choi YH, et al. (2012) Obesity activates Toll-like receptor-mediated proinflammatory signaling cascades in the adipose tissue of mice. J Nutr Biochem 23, 113-122.

25. Kim F, Pham M, Luttrell I, et al. (2007) Toll-like receptor-4 mediates vascular inflammation and insulin resistance in diet-induced obesity. Circ Res 100, 1589-1596.

26. Jacob PS, de Meneses Fujii TM, Yamada M, et al. (2013) Isocaloric intake of a high-fat diet promotes insulin resistance and inflammation in Wistar rats. Cell Biochem Funct 31, 244-253.

27. Lai YH, Chen LJ \& Cheng JT (2013) Role of TNF- $\alpha$ in renal damage in mice showing hepatic steatosis induced by high fat diet. Horm Metab Res 45, 38-42.

28. Park HJ, Lee J, Chung M, et al. (2012) Green tea extract suppresses $\mathrm{NF \kappa B}$ activation and inflammatory responses in diet-induced obese rats with nonalcoholic steatohepatitis 1-3. J Nutr 142, 57-63.

29. Nascimento AF, Sugizaki MM, Leopoldo AS, et al. (2008) A hypercaloric pellet-diet cycle induces obesity and co-morbidities in Wistar rats. Arq Bras Endocrinol Metabol 52, 968-974.

30. Luvizotto RDAM, Nascimento AF, Imaizumi E, et al. (2013) Lycopene supplementation modulates plasma concentrations and epididymal adipose tissue mRNA of leptin, resistin and IL-6 in diet-induced obese rats. Br J Nutr 110, 1803-1809.

31. Gea-Sorlí S, Bonjoch L \& Closa D (2012) Differences in the inflammatory response induced by acute pancreatitis in different white adipose tissue sites in the rat. PLOS ONE 7, e41933.

32. Ferron AJ, Jacobsen BB, Sant'Ana PG, et al. (2015) Cardiac dysfunction induced by obesity is not related to $\beta$-adrenergic system impairment at the receptor-signalling pathway. PLOS ONE 10, e0138605.

33. Matthews DR, Hosker JP, Rudenski AS, et al. (1985). Homeostasis model assessment: insulin resistance and $\beta$-cell function from fasting plasma glucose and insulin concentrations in man. Diabetologia 28, 1985.

34. Bradford MM (1976) A rapid and sensitive method for the quantitation of microgram quantities of protein utilizing the principle of protein-dye binding. Anal Biochem 72, 248-254.

35. Osman OS, Selway JL, Kępczyńska MA, et al. (2013) A novel automated image analysis method for accurate adipocyte quantification. Adipocyte 2, 160-164. 
36. World Health Organization (2016) World Health Organization obesity and overweight fact sheet. http://www.who.int/mediacentre/factsheets/fs311/en/

37. Strissel KJ, Denis GV \& Nikolajczyk BS (2014) Immune regulators of inflammation in obesity-associated type 2 diabetes and coronary artery disease. Curr Opin Endocrinol Diabetes Obes 21, 330-338.

38. Ouchi N, Parker JL, Lugus JJ, et al. (2011) Adipokines in inflammation and metabolic disease. Nat Rev Immunol 11, 85-97.

39. Hotamisligil GS (2006) Inflammation and metabolic disorders. Nature 444, 860-867.

40. Ye J (2013) Mechanisms of insulin resistance in obesity. Front Med 7, 14-24.

41. Soumaya K (2012) Molecular mechanisms of insulin resistance in diabetes. Adv Exp Med Biol 771, 250-251.

42. Cacho J, Sevillano J, de Castro J, et al. (2008) Validation of simple indexes to assess insulin sensitivity during pregnancy in Wistar and Sprague Dawley rats. Am J Physiol Endocrinol Metab 295, E1269_ E1276.

43. Sampey BP, Vanhoose AM, Winfield HM, et al. (2011) Cafeteria diet is a robust model of human metabolic syndrome with liver and adipose inflammation: comparison to high-fat diet. Obesity (Silver Spring) 19, 1109-1117.

44. Panchal SK, Poudyal H, Iyer A, et al. (2011) High-carbohydrate, high-fat diet-induced metabolic syndrome and cardiovascular remodeling in rats. J Cardiovasc Pharmacol 57, 611-624.

45. Paniagua JA, Escandell-Morales JM, Gil-Contreras D, et al. (2014) Central obesity and altered peripheral adipose tissue gene expression characterize the NAFLD patient with insulin resistance: role of nutrition and insulin challenge. Nutrition 30, 177-185.
46. Paniagua JA (2016) Nutrition, insulin resistance and dysfunctional adipose tissue determine the different components of metabolic syndrome. World J Diabetes 7, 483-514.

47. Monteiro R \& Azevedo I (2010) Chronic inflammation in obesity and the metabolic syndrome. Mediators Inflamm 2010, article ID 289645.

48. Chatzigeorgiou A \& Chavakis T (2015) Immune cells and metabolism. Handb Exp Pharmacol 233, 251-263.

49. Kraakman MJ, Murphy AJ, Jandeleit-Dahm K, et al. (2014) Macrophage polarization in obesity and type 2 diabetes: weighing down our understanding of macrophage function? Front Immunol $5,470$.

50. Fjeldborg K, Pedersen SB, Møller HJ, et al. (2014) Human adipose tissue macrophages are enhanced but changed to an antiinflammatory profile in obesity. J Immunol Res 2014, 309548.

51. Shaul ME, Bennett G, Strissel KJ, et al. (2010) Dynamic, M2-like remodeling phenotypes of $\mathrm{CD} 11 \mathrm{c}+$ adipose tissue macrophages during high-fat diet-induced obesity in mice. Diabetes 59, 1171-1181.

52. Nishimura S, Manabe I, Nagasaki M, et al. (2009) CD8+ effector T cells contribute to macrophage recruitment and adipose tissue inflammation in obesity. Nat Med 15, 914-920.

53. Erridge C \& Samani NJ (2009) Saturated fatty acids do not directly stimulate Toll-like receptor signaling. Arterioscler Thromb Vasc Biol 29, 1944-1949.

54. Shi H, Kokoeva MV, Inouye K, et al. (2006) TLR4 links innate immunity and fatty acid-induced insulin resistance. J Clin Invest 116, 3015-3025.

55. Schenk S, Saberi M \& Olefsky JM (2008) Insulin sensitivity: modulation by nutrients and inflammation. J Clin Invest 118, 2992-3002. 